\title{
A Simultaneous Equations Model of Fiscal Policy Interactions
}

\author{
Maarten A. Allers (Corresponding author) \\ Faculty of Economics and Business, and \\ Center for Research on Local Government Economics (COELO) \\ University of Groningen \\ PO Box 800, 9700AV Groningen, Netherlands. \\ Phone: +31 50 3633745; Fax +31 50 3637337; E-mail m.a.allers@rug.nl.

\section{J. Paul Elhorst} \\ Faculty of Economics and Business \\ University of Groningen \\ PO Box 800, 9700AV Groningen, Netherlands.
}

\begin{abstract}
Existing studies of fiscal policy interactions are based on single equation models of either taxation or expenditures, without specifying the underlying social welfare function, without taking account of budget constraints and without allowing for cost differences between jurisdictions. Taking all this into account, we derive an extended version of the linear expenditure system (LES) with policy interaction effects. We use this system to simultaneously estimate interactions in both taxation and different spending categories among Dutch municipalities. Our interaction parameters tend to be higher than those estimated using conventional single equation models.
\end{abstract}

JEL classification: $\mathrm{C} 31, \mathrm{H} 71, \mathrm{H} 72$

Keywords: fiscal policy interaction, tax mimicking, spending needs, spatial econometrics, linear expenditure system.

Acknowledgements

The authors thank Adriaan Soetevent and the anonymous referees for useful comments on a previous version of this paper. 
Recent studies suggest that fiscal policies are to a considerable extent influenced by fiscal policies in neighboring jurisdictions. Many of these studies focus on tax policy and find that tax rates depend in part on tax rates in nearby jurisdictions: an increase in the tax burden in neighboring jurisdictions of one unit is matched by an increase ranging from 0.2 to 0.6 in a jurisdiction's own tax burden. A related strand of literature focuses on expenditure interaction effects and has found similar results. ${ }^{1}$

Empirical studies of fiscal policy interaction tend to consider either taxation or expenditures for one public service at a time, and are mostly based on the spatial lag model. The spatial lag model is a single equation model where the dependent variable is taken to depend on its spatially lagged value and a set of control variables (see Anselin, 2006). The dependent variable measures tax setting or spending on public services in the jurisdiction itself, while its spatial lagged value measures tax setting or spending on public services in neighboring jurisdictions. In this model, the coefficient of the spatially lagged dependent variable is interpreted as the degree of interaction among jurisdictions.

A limitation of the single equation approach directed at taxation or at one particular expenditure category is that it ignores the local government's budget constraint, which links spending to taxation, as well as spending in one service sector to spending in other service sectors. Consequently, existing studies overlook the possibility that observed spatial patterns in taxes may be the result of expenditure interdependence (these expenditures being financed through taxation), and that observed spatial patterns in one expenditure category may be the result of tax interdependence or of spatial interdependencies among other expenditure categories. Some studies do investigate both taxes and expenditures, but as long as these are analyzed separately (Schaltegger and Küttel, 2002; Revelli, 2002) and not simultaneously, it is not possible to discriminate among these interdependencies.

A few recent studies seem to realize the limitations of focusing on either taxation or expenditures, and study interactions in local government efficiency, i.e., output divided by revenue (Geys, 2006; Revelli and Tovmo, 2007). This approach is consistent with the yardstick competition hypothesis stating that citizens judge incumbent politicians by comparing the value for money they receive from their own government with the value for money enjoyed by inhabitants of nearby jurisdictions. A problem inherent in this approach is the measurement of local government output. Typically, local governments have a broad range of responsibilities, and produce outputs that are notoriously difficult to measure 
accurately. Except for single-purpose jurisdictions like school districts or water boards, a single output measure has limited usefulness. In this paper we present an approach that offers the opportunity to make a distinction between different expenditure categories and between expenditures and taxation and to estimate the interaction effect in each of these fields.

A second limitation of previous work on expenditure interaction is that it implicitly assumes that a certain spending level yields the same service level in every community. That is clearly not realistic. Jurisdictions face different unit costs. The higher these costs, the more expenditures are needed to supply citizens with the same service level. Such differences in spending needs ${ }^{2}$ are an important rationale for many fiscal equalization schemes that exist around the world (Ladd and Yinger, 1994). However, most studies analyze interactions without correcting for differences in spending needs.

A third limitation of existing empirical studies of fiscal policy interactions is that the spatially lagged variable is usually introduced into the model in a sort of ad hoc manner that lacks a firm theoretical foundation. The functional form of the social welfare function that underlies the spatial lag model is not specified.

The purpose of this paper is to fill these gaps. We develop a theoretical framework for modeling fiscal policy interaction. We start from three existing theoretical explanations why the local government's social welfare function may contain tax rates and service levels in other jurisdictions as arguments. We operationalize the resulting social welfare function by adopting a Stone-Geary functional form and show that an extended version of the linear expenditure system (LES) results if social welfare is maximized under a government's budget constraint. In this LES, the committed expenditures of a particular government are taken to depend on the expenditures of other governments that belong to its reference group. Since we do not make the assumption that unit costs are the same in every jurisdiction, the extended LES will also contain a term accounting for differences in unit costs. To the best of our knowledge, such a model has not been derived before, let alone estimated. We discuss the pros and cons of this system in relation to the existing empirical literature, and we estimate it using data on local governments in the Netherlands. By comparing the results of our extended LES with those of single equation models, we find that single equation parameter estimates of fiscal interaction tend to be downwardly biased.

This paper is organized as follows. In Section 2 we formulate a social welfare function containing tax and expenditure interactions and use that to derive a system of demand equations that can be empirically estimated. In Section 3 we describe the estimation procedure of our simultaneous equations system. In Section 4 we use this system to test for 
interactions among 496 municipalities in the Netherlands with respect to taxation and six different public expenditure sectors. In Section 5 we present our conclusion, and make suggestions for further research.

The following notation is useful: the index $i$ is used to denote jurisdictions (or municipalities) and the index $\_i$ or $j$ to denote jurisdictions with which jurisdiction $i$ 's fiscal policy interacts (referred to as 'neighbors'); the index $m$ is used to denote a particular public service and the index $n$ to sum over these public services; the indices $g$ and $h$ are used to denote two different sets of explanatory variables. The total number of jurisdictions or municipalities is $N$, the total number of public services is $M$, and the total number of explanatory variables is $G$ and $H$, respectively.

\section{A MODEL FOR FISCAL POLICY INTERACTIONS}

\section{Three theoretical models}

We build on Brueckner's (2003) and Revelli's (2005) analysis of the three existing theoretical models which predict strategic interactions. The first of these is the spillover model. Consider a set of $N$ local jurisdictions. The government in each jurisdiction is in charge of providing services and of raising taxes to fund the expenditures on these publicly provided services. Suppose that the representative individual living in jurisdiction $i(i=1, \ldots, N)$ has income $y_{i}$ and receives utility from private consumption and from services provided by the local government. However, some of these services also benefit individuals living in other jurisdictions. People may, e.g., use parks or health facilities in other localities. The consumer's utility function taking account of these spillovers is given by

$$
U\left(\left(1-t_{i}\right) y_{i}, Q_{i 1}, \ldots, Q_{i M}, Q_{-}{ }_{i 1}, \ldots, Q_{-} i M, X_{i}\right)
$$

where $t_{i}$ is the tax rate and $\left(1-t_{i}\right) y_{i}$ is income net of taxes, available for private consumption. $Q_{i m}$ denotes the per capita level of a publicly provided service $m(m=1, \ldots, M)$ of government $i$, while $Q_{i}$ im is a compound term of the level of publicly provided service $m$ of neighboring governments. Finally, preferences are affected by $X_{i}$, which denotes characteristics of jurisdiction $i$.

Instead of one consumer, we may have different consumers in every jurisdiction with preferences ranging along a spectrum on most public services. The median voter theorem states that, if preferences are single-peaked and government policy is decided by 
representatives elected by a majority vote, government policy will reflect the preferences of the median voter. Consequently, local government $i$ 's social welfare function may be written as

$$
V\left(t_{i}, Q_{i 1}, \ldots, Q_{i M}, Q_{-} i 1, \ldots, Q_{-} i M, X_{i}\right) .
$$

Government $i$ chooses the bundle of taxes and service levels that maximizes social welfare, setting $\partial V / \partial t_{i}=0$ and $\partial V / \partial Q_{i m}=0 \quad(m=1, . ., M)$. Because these derivatives depend on government's $i$ own characteristics $X_{i}$ and on choices elsewhere $Q_{-} i m(m=1, \ldots, M)$, the solutions can be written as

$$
t_{i}=R_{0}\left(Q_{-} i 1, \ldots, Q_{-} i M, X_{i}\right) \text { and } Q_{i m}=R_{m}\left(Q_{-} 11, \ldots, Q_{-} i M, X_{i}\right) \quad(m=1, \ldots, M),
$$

where $R$ represent reaction functions, which give government $i$ 's best responses to the choices of other governments. Note that the slope of these reaction functions can be positive or negative. Further note that in this simple spillover model, interactions only exist if people benefit from public services provided elsewhere, and that taxes set in jurisdiction $i$ do not interact with those in other jurisdictions. However, as services are financed through taxation, estimation of a tax interaction effect using a single equation model may well yield a significant result even though it does not in fact exist.

The second theoretical model that predicts strategic policy interaction is the yardstick competition model. The yardstick competition hypothesis, introduced by Salmon (1987) and further developed by Besley and Case (1995) and others, states that tax setting and local government service levels in one jurisdiction interact with tax setting and local government service levels in neighboring jurisdictions as a result of asymmetric information. Voters do not know what level of public services can be provided relative to a certain tax level and therefore use information from other jurisdictions to judge the performance of their own government. Tax rates and service levels in nearby jurisdictions can serve as a benchmark and be used to re-elect good incumbents and to boot out bad ones. If voters consider relative performance, rational politicians will do the same and (partly) mimic tax rates and service levels of their neighbors in order to increase their chances of re-election. This is the case unless incumbents face binding term limits or are relatively confident of reelection, in which case they enjoy more freedom to delineate their own policy. 
Let $\sum_{m} Q_{i m} / t_{i}$ denote the minimum level of services relative to the tax rate that must be delivered for jurisdiction's $i$ government to remain in office. This required level depends on observed service levels and tax rates in other jurisdictions: $\sum_{m} Q_{i m} / t_{i}=\pi\left(\left[\sum_{m} Q_{m} / t\right]_{-} i\right)$. In other words, if the level of public service provision relative to taxes in other jurisdictions increases, government $i$ is forced to raise its service level or to lower its taxes to remain in office according to a function $\pi$. Substitution of $t_{i}=\sum_{m} Q_{i m} / \pi\left(\left[\sum_{m} Q_{m} / t\right]_{-}\right)$into the utility function of the median voter (Eq. 1) gives

$$
U\left(y_{i}\left(1-\sum_{m} Q_{i m} / \pi\left(\left[\sum_{m} Q_{m} / t\right]_{-} i\right)\right), Q_{i 1}, \ldots, Q_{i M}, Q_{-} i 1, \ldots, Q_{-} i M, X_{i}\right) .
$$

The utility function under yardstick competition, Eq. (4), results in the following social welfare function for government $i$

$$
V\left(t_{i}, Q_{i 1}, \ldots, Q_{i M}, t_{-}, Q_{-}{ }_{i 1}, \ldots, Q_{-}{ }_{i}, X_{i}\right) .
$$

This welfare function differs from the welfare function in the spillover case, Eq. (2), because it contains $t_{-}$. The reaction functions in Eq. (3) now change into

$$
t_{i}=R_{0}\left(t_{-}, Q_{-} i 1, \ldots, Q_{-} i M, X_{i}\right) \text { and } Q_{i m}=R_{m}\left(t_{-}, Q_{-} i 1, \ldots, Q_{-} i M, X_{i}\right) \quad(m=1, \ldots, M) .
$$

The third theoretical model predicting strategic policy interaction applies to competition for mobile resources (e.g., tax competition; Tiebout, 1956; Wilson, 1999). This kind of competition between jurisdictions results if the distribution of particular resources over jurisdictions is affected by the bundle of local taxes and service levels relative to other jurisdictions. One example of such a resource is mobile capital. More mobile capital within the jurisdiction leads to a higher demand for labor, and higher income levels due to higher wage rates as well as income from capital ownership. Mobile capital can be attracted by offering certain public services, but at the same time be chased off by taxes needed to fund these services. The total amount of mobile capital within a jurisdiction will therefore depend on the net-of-tax returns of that jurisdiction relative to others.

The distribution of the resource over jurisdictions depends on tax rates, public service levels, and local characteristics. The resource $s_{i}$ that resides within the borders of jurisdiction $i$ is given by 


$$
s_{i}=S\left(t_{i}, Q_{i 1}, \ldots, Q_{i M}, t_{-}, Q_{-}{ }_{i 1}, \ldots, Q_{-} i M, X_{i}, X_{-}\right) .
$$

Since the availability of resource $s_{i}$ affects the income level $y_{i}$ in jurisdiction $i, y_{i}=y_{i}\left(s_{i}\right)$, the utility function of the median voter, Eq. (1), changes into

$$
U\left(\left(1-t_{i}\right) y_{i}\left[S\left(t_{i}, Q_{i 1}, \ldots, Q_{i M}, t_{-} i, Q_{-} i 1, \ldots, Q_{-} i M, X_{i}, X_{-}\right], Q_{i 1}, \ldots, Q_{i M}, Q_{-} i 1, \ldots, Q_{-} i M, X_{i}\right) .\right.
$$

The utility function under resource competition, Eq. (8), results in the following social welfare function for government $i$

$$
V\left(t_{i}, Q_{i 1}, \ldots, Q_{i M}, t_{-}, Q_{-} i 1, \ldots, Q_{-} i M, X_{i}, X_{-}\right) \text {. }
$$

Like the welfare function in the yardstick competition case, Eq. (5), this welfare function differs from the welfare function in the spillover case, Eq. (2), because it contains $t_{-} i$. Similarly, it differs from the welfare function under yardstick competition, Eq. (5), because it contains $X_{-}$. The reaction functions in Eq. (3) now change into

(10) $t_{i}=R_{0}\left(t_{-}, Q_{-} i 1, \ldots, Q_{-} i M, X_{i}, X_{-}\right)$and $Q_{i m}=R_{m}\left(t_{-}, Q_{-} i 1, \ldots, Q_{-} i M, X_{i}, X_{-}\right) \quad(m=1, \ldots, M)$.

In sum, both yardstick competition and resource competition offer an explanation for tax as well as service level interaction effects among local governments, while a third possible explanation for service level interaction effects (but not for tax interaction) is the existence of spillovers.

Previous empirical work (see endnote 1) models interactions in expenditure levels not service levels. It is important to note that this implicitly assumes that there are no differences in spending needs as a result of which some jurisdictions need to spend more than others in order to supply a certain service level. We do not make that assumption.

Because the welfare function Eq. (9) and the associated reaction functions Eq. (10), which contain both $t_{-}, Q_{-} i 1, \ldots, Q_{-} i M$, and $X_{-}$, are more general than their counterparts in Eqs. (2) and (3), which do not contain $t_{-} i$ and $X_{-}$, and than their counterparts in (5) and (6), which do not contain $X_{-}$, we will base our model on these functions. If such a model is estimated in the case where interactions are solely driven by spillovers, the tax interaction effect will be zero. 


\section{Social Welfare Maximization with Interactions}

Assuming that running a deficit or borrowing to finance expenditures are not allowed, the budget constraint for local government $i$ is given by

$$
\sum_{m=1}^{M} p_{i m} Q_{i m}=T_{i}+\Pi_{i}
$$

where $T_{i}$ is per capita tax revenue, $\Pi_{i}$ is per capita exogenous income, such as lump-sum grants from the central government, and $p_{i m}$ is the unit cost of public service $m$. To ease the notation below, tax revenue $T_{i}$ is treated as a negative expenditure

$$
\sum_{m=0}^{M} p_{i m} Q_{i m}=\Pi_{i} \text {, with } p_{i 0} Q_{i 0}=-T_{i} \text {. }
$$

Since $Q_{i m}$ are decision variables that interact across borders, and $p_{i m}$ translates $Q_{i m}$ into expenditure or revenue levels, $Q_{i 0}$ should be interpreted as the tax rate and $p_{i 0}$ is the tax base.

To operationalize the social welfare function in Eq. (9), we adopt the Stone-Geary functional form. This form has been used frequently in studies of social interactions (Kapteyn et al., 1997; Brock and Durlauf, 2001; Kooreman and Schoonbeek, 2004; Soetevent, 2004; Grodner and Kniesner, 2006). It is convenient for introducing interactions in a theoretically satisfactory manner through its structural parameters

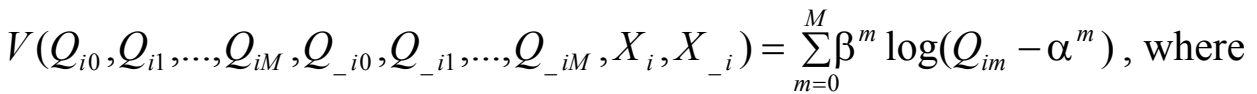

$$
\begin{aligned}
& \sum_{m=0}^{M} \beta^{m}=1
\end{aligned}
$$

The welfare $V$ derived from a particular public service $m$ is a function of the service level in excess of the committed or subsistence level $\alpha^{m}$, and of preferences, which determine $\beta^{m}$ (the functional forms of $\alpha^{m}$ and $\beta^{m}$ will be introduced below). The Stone-Geary function can only usefully be applied in cases where all public services are normal and all pairs of public services are net substitutes. As long as local public services are categorized into a limited number of broad groups, these conditions are likely to be met. Another limitation is that the 
Stone-Geary function is only defined if $Q_{i m}>\alpha^{m}$ for all public services, known as the limited domain problem.

Policy interaction is introduced by embedding $Q_{-} i m$ into the committed service level parameters $\alpha^{m}$

$$
\alpha^{m}=\delta_{m} Q_{-i m}+\dot{\alpha}^{m}
$$

Consequently, $\alpha^{m}$ measures the committed service level with policy interaction effects and $\dot{\alpha}^{m}$ the committed service level without policy interaction effects. The parameter $\delta_{m}$ represents the importance of interaction effects and can be either negative or positive. In the spillover model, $\delta_{m}$ is likely to be negative. Here, $\delta_{m} Q_{-} i m$ represents the contribution of service levels in other jurisdictions to the locally available service level, as a result of which, subsistence levels provided by the local government can be lower than without spillovers. In the yardstick competition model, $\delta_{m}$ is likely to be positive. Here, $\delta_{m} Q_{-} i m$ describes the service level that citizens take for granted because it concerns services that inhabitants of other jurisdictions also enjoy.

Maximizing the social welfare function subject to the budget constraint yields the following Linear Expenditure System (LES) ${ }^{3}$

$$
p_{\text {im }} Q_{\text {im }}=p_{\text {im }} \delta_{m} Q_{-i m}+p_{\text {im }} \dot{\alpha}^{m}+\beta^{m}\left[\Pi_{i}-\sum_{n=0}^{M}\left(p_{\text {in }} \delta_{n} Q_{-i n}+p_{i n} \dot{\alpha}^{n}\right)\right], \quad m=0, \ldots, M,
$$

or, if we replace $p_{i m} Q_{i m}$ by $E_{i m}$ (expenditures) and $p_{i m} \dot{\alpha}^{m}$ by $\ddot{\alpha}^{m}$ (subsistence expenditures),

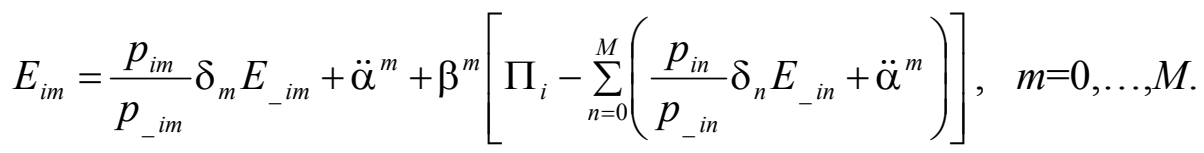

Expenditures on public service $m$ are equal to committed expenditures on this service $\left(p_{\text {im }} / p_{-i m}\right) \delta_{m} E_{-i m}+\ddot{\alpha}^{m}$ plus a fraction $\beta^{m}$ of discretionary income, that is, the income which remains after all committed expenditures have been financed. Note that we use a different index ( $n$ instead of $m$ ) to compute the sum of these committed expenditures. One advantage of $\left(15^{\prime}\right)$ is that it is not necessary to distinguish prices and quantities. Existing empirical work 
(endnote 1) studies interactions in expenditure levels not service levels, since a difficult issue is the lack of adequate output measures for public services and the difficulties in deriving unit costs for public services from factor input prices (see Aaberge and Langørgen, 2003, for an extensive discussion). Although other demand systems may be more flexible in prices, ${ }^{4}$ the LES is one of the few systems where prices $(p)$ and quantities $(Q)$ are not separated from each other, as a result of which expenditure data suffices $(E=p Q)$. This increases the empirical applicability of the LES relative to other systems.

Since we do not assume, as many previous studies have done implicitly, that $p_{i m}$ equals $p_{-} i m$, committed expenditures depend partly on $p_{i m} / p_{-} i m$, the relative unit cost of service $m$. That is because relative unit costs determine how much expenditure is needed to provide service levels similar to those in other jurisdictions. If jurisdictions within the reference group of jurisdiction $i$ need to spend more than jurisdiction $i$ to supply a standard service level, these higher expenditures do not affect committed expenditures in jurisdiction $i$. As far as we know, previous studies of fiscal policy interaction do not systematically incorporate the fact that some jurisdictions need to spend more than others in order to supply their citizens with a standard service level. ${ }^{5}$

For $E_{i 0}$, tax revenue, which we defined as a negative expenditure, committed expenditures $\left(p_{i 0} / p_{-} i 0\right) \delta_{0} E_{-} i 0+\ddot{\alpha}^{0}$ can be interpreted as the maximum acceptable tax revenue (Johnson, 1979). Discretionary income can be spent on expenditure categories 1 to $\mathrm{M}$, or used to lower tax revenue, which is smaller than or equal to $\left(p_{i 0} / p_{-} i 0\right) \delta_{0} E_{-} i 0+\ddot{\alpha}^{0}$. Instead of the relative unit price, $p_{i 0} / p_{i} i 0$ denotes the relative tax base, which determines what revenue level corresponds to a certain tax rate.

Following Pollak and Wales (1981), we further extend the system by "translating" $\ddot{\alpha}^{m}$ and $\beta^{m}$. First, we make discretionary income spending dependent on local preferences

$$
\beta_{i}^{m}=\beta_{m 0}+\sum_{g=1}^{G} \beta_{m g} X_{i g}
$$

where $X_{i g}$ are exogenous variables that determine the share of discretionary income that is spent on public service $m$ in jurisdiction $i$, and $\beta_{m g}(g=0, \ldots, G)$ are unknown coefficients to be estimated. The share of discretionary income now depends on variables that are different from one jurisdiction to the other $\left(X_{i g}\right)$. For this reason $\beta_{i}^{m}$ should contain the subscript $i$. 
Further note that the nature and the number of exogenous variables is the same for each service sector, but that the coefficients are normally different for different public services.

Similarly, following Aaberge and Langørgen (2003) and Jackman and Papadachi (1981), we assume that regulations and public pressure set minimum service standards across governments ( $\dot{\alpha}^{m}$ is the same for every jurisdiction), but that expenditures associated with those uniform minimum requirements $\ddot{\alpha}^{m}$ depend on exogenous variables $S_{i m h}\left(h=1, \ldots, H_{m}\right)$. We use the symbol $S$ instead of $X$ to distinguish these two different sets of variables. For example, a community with a large share of schoolchildren in its population needs to spend more per capita to attain a certain educational service level than other communities. From the literature on fiscal disparities, it is well known that jurisdictions may differ considerably with respect to spending needs, i.e., the amount they need to spend to reach a certain service level (e.g., Ladd and Yinger, 1994). Thus, we define

$$
\ddot{\alpha}_{i}^{m}=\alpha_{m 0}+\sum_{h=1}^{H_{m}} \alpha_{m h} S_{i m h}
$$

where $\alpha_{m h}\left(h=0, \ldots, H_{m}\right)$ are unknown coefficients to be estimated. Note that the nature and the number of the exogenous variables $S_{m h}$, in contrast to the variables $X_{g}$, may be different for different public services.

Recall that $\ddot{\alpha}_{i}^{m}$ is defined as $p_{i m} \dot{\alpha}^{m}$ and that the subsistence service level $\dot{\alpha}^{m}$ has been assumed to be the same for every jurisdiction. Consequently, from (17) we derive

$$
\frac{p_{i m}}{p_{-i m}}=\frac{\alpha_{m 0}+\sum_{h=1}^{H_{m}} \alpha_{m h} S_{i m h}}{\alpha_{m 0}+\sum_{h=1}^{H_{m}} \alpha_{m h} S_{-i m h}} .
$$

By substituting Eqs. (16), (17) and (18), the $m^{\text {th }}$ equation of the LES in Eq. (15') can finally be rewritten as

$$
E_{i m}=\frac{\alpha_{m 0}+\sum_{h=1}^{H_{m}} \alpha_{m h} S_{i m h}}{\alpha_{m 0}+\sum_{h=1}^{H_{m}} \alpha_{m h} S_{-i m h}} \delta_{m} E_{-i m}+\alpha_{m 0}+\sum_{h=1}^{H_{m}} \alpha_{m h} S_{i m h}
$$




$$
+\left(\beta_{m 0}+\sum_{g=1}^{G} \beta_{m g} X_{i g}\right)\left[\Pi_{i}-\sum_{n=0}^{M}\left\{\frac{\alpha_{n 0}+\sum_{h=1}^{H_{n}} \alpha_{n h} S_{i n h}}{\alpha_{n 0}+\sum_{h=1}^{H_{n}} \alpha_{n h} S_{-i n h}} \delta_{n} E_{-i n}+\alpha_{n 0}+\sum_{h=1}^{H_{n}} \alpha_{n h} S_{i n h}\right\}\right] .
$$

\section{To an Empirical System of Equations with Interactions}

To be able to estimate the extended LES, the interaction variables $E_{-} i m$ and $S_{-} i m$ must be operationalized. The standard solution to this problem in the spatial econometrics literature is to impose prior information about the nature of interactions over space. These interactions can be modeled by a spatial weights matrix $\boldsymbol{W}$, a pre-specified nonnegative matrix of order $N$ describing the spatial arrangement of the jurisdictions in the sample. The diagonal elements of $\boldsymbol{W}$ are set to zero by convention to avoid that governments belong to their own reference group. For ease of interpretation, it is also common practice to normalize $\boldsymbol{W}$ such that the elements of each row sum to unity. Since $\boldsymbol{W}$ is nonnegative, this ensures that all its elements are in the range $[0,1]$.

Let $w_{i j}$ denote a particular element of the spatial weights matrix $\boldsymbol{W}(i, j=1, \ldots, N)$, then the interaction variables $E_{-} i m$ and $S_{-i m h}$ of government $i$ are defined as weighted averages of neighboring values of those governments within the reference group: $E_{-} i m=\sum_{j=1}^{N} w_{i j} E_{j m}$ and $S_{-i m h}=\sum_{j=1}^{N} w_{i j} S_{j m h}$, respectively, where the subscript $j$ replaces the subscript $i$. The full model for every single government $i$ involving a system of $M+1$ equations can then be written as

$$
E_{i 0}=\gamma_{i 0} \sum_{j=1}^{N} \delta_{0} w_{i j} E_{j 0}+\alpha_{00}+\sum_{h=1}^{H_{0}} \alpha_{0 h} S_{i 0 h}+\left(\beta_{00}+\sum_{g=1}^{G} \beta_{0 g} X_{i g}\right) \Phi_{i}+\varepsilon_{i 0}
$$

(20c) $\quad \sum_{m=0}^{M} \beta_{m 0}=1, \sum_{m=0}^{M} \beta_{m g}=0$ for $g=1, \ldots, G$,

(20d) $\quad E\left(\varepsilon_{i m}\right)=0, E\left(\varepsilon_{i m} \varepsilon_{i n}^{\prime}\right)=\sigma_{m n}$ for $m, n=0, \ldots, M$,

where $\Phi_{i} \equiv \Pi_{i}-\sum_{n=0}^{M}\left\{\gamma_{i n} \sum_{j=1}^{N} \delta_{n} w_{i j} E_{j n}+\alpha_{n 0}+\sum_{h=1}^{H_{n}} \alpha_{n h} S_{i n h}\right\}$ is discretionary income, and $\gamma_{i m} \equiv \frac{\alpha_{m 0}+\sum_{h=1}^{H_{m}} \alpha_{m h} S_{i m h}}{\alpha_{m 0}+\sum_{h=1}^{H_{m}} \sum_{j=1}^{N} \alpha_{m h} w_{i j} S_{j m h}}=\frac{p_{i m}}{\sum_{j=1}^{N} w_{i j} p_{j m}}$ is the relative cost of the provision of service 
$m$ (see Eq. 18). The adding-up restrictions in Eq. (20c) ensure that expenditures of government $i$ sum to $\Pi_{i}$. The error terms in the different equations are assumed to be correlated, which is known as contemporaneous error correlation and as the Seemingly Unrelated Regressions (SUR) model. Such a specification is reasonable when the error terms for different expenditure categories are likely to reflect some common immeasurable or omitted factors.

The system of equations in (20) demonstrates the differences with previous studies of fiscal policy interaction (listed in endnote 1), which are based on the spatial lag model. This is a single equation model where the dependent variable, in addition to a set of control variables, is taken to depend on its spatial lagged value (see Anselin, 2006). ${ }^{6}$ Studies using one or a set of different single equation spatial lag models, one for every type of public services, differ from our study based on (20) in four respects. They set:

$$
\begin{aligned}
& \alpha_{n h}=0 \text { as part of } \Phi_{i}, \text { for } n=0, \ldots, M ; h=0, \ldots, H_{n}, \\
& \delta_{n}=0 \text { as part of } \Phi_{i}, \text { for } n=0, \ldots, M, \\
& \sigma_{m n}=0 \text { as part of }(20 \mathrm{~d}), \text { for } m \neq n ; m, n=0, \ldots, M .(21 \mathrm{c}) \\
& \gamma_{i m}=1 \text { as part of the whole system, for } m=0, \ldots, M .
\end{aligned}
$$

These restrictions show how our model extends previous research. The first restriction (21a) shows why our extended LES, even though it is based on the assumption that all public services are normal and to be substitutes of each other, is more general than a set of different single equation studies. In a single equation model, expenditures on a particular public service are seen as depending on their own cost variables $S_{m h}$ only, whereas in the LES they are also seen as depending on the cost variables of other public services. This is because the LES explicitly takes account of the local government's budget constraint. The second difference (21b) shows that we did not introduce the spatially lagged value into the demand equation in a sort of "ad hoc" manner that lacks a theoretical foundation. Instead, following the social interactions literature, we introduced it by making the committed expenditures in the Stone-Geary social welfare function on a particular public service of a particular government dependent on the expenditures on that public service of other governments that belong to its reference group. The result is that the expenditures on a particular public service not only interact with the same expenditures of other governments, but also with the expenditures of those governments on other public services. This result can again be 
attributed to the local government's budget constraint. The third difference (21c) demonstrates that a set of single equation models imposes zero correlations between the error terms of the different equations of the model, leading to a loss of efficiency: the parameter estimates will be correct, but their confidence intervals will increase (Srivastava and Giles, 1987). The fourth condition (21d) highlights that we do not make the assumption that unit costs are equal in all jurisdictions.

\section{$3 \quad$ ESTIMATION PROCEDURE}

In this section we will describe the estimation procedure for our model. Kapteyn et al. (1997) already dealt with the problem of interdependent preferences within a linear expenditure system, building on the previous work of Gaertner (1974) and Pollak (1976), but they use a simpler model, and were only able to estimate the reduced form parameters.

In his seminal textbook on spatial econometrics, Anselin (1988, pp. 138-145 and pp. 157-162) describes how to estimate a spatial SUR model by Maximum Likelihood (ML). A spatial SUR model is a system with one equation for each cross-section of $\mathrm{N}$ spatial units at each point in time extended to include a spatially autocorrelated error term or a spatially lagged dependent variable. In Anselin's model, the regression coefficients are constant across space but vary over time. Our model is different because we do not have a different crosssection of observations for each year, but instead different types of public services for the same cross-section of observations. Consequently, the regression coefficients do not vary over time but over the types of public services. Moreover, there are three complications. First, the extended linear expenditure system is nonlinear in both the $\alpha, \beta$ and $\delta$ parameters and the explanatory variables. ${ }^{7}$ Second, the system of equations has cross-equation restrictions, since the same $\alpha$ and $\delta$ parameters enter into all of the equations. Third, the likelihood function contains a Jacobian term that is far more complicated.

The log-likelihood function of the model in (20) is

$$
\log L=-\frac{\mathrm{N}}{2} \ln |\boldsymbol{\Omega}|-\frac{1}{2} \boldsymbol{e}^{T}\left(\boldsymbol{\Omega}^{-1} \otimes \boldsymbol{I}_{N}\right) \boldsymbol{e}+\ln |\boldsymbol{J}|
$$

Usually, one equation is eliminated to avoid any singularity caused by the adding-up restrictions. Theoretically, the results are invariant no matter which equation is eliminated. If we eliminate the $M^{\text {th }}$ equation, $\boldsymbol{\Omega}$ is a symmetric $M \times M$ matrix, $\boldsymbol{\Omega}=\left[\sigma_{i j}\right](i, j=0, \ldots, M-1)$, and $\boldsymbol{e}$ is an $N M \times 1$ vector containing the residuals of the model. These residuals are assumed to be 
sorted first by equation (i.e., type of public services) and then by spatial unit. $\boldsymbol{J}$ denotes the Jacobian term of the transformation from the vector of error terms $\varepsilon$ to the vector of the dependent variables $\boldsymbol{E}$. This Jacobian term should be calculated over all $M+1$ equations. Consequently, $\boldsymbol{J}$ is an $(M+1) N \times(M+1) N$ matrix that takes the following form

(23) $\boldsymbol{J}=\boldsymbol{I}_{(M+1) N}-\left[\begin{array}{ccc}\delta_{0} \boldsymbol{\Gamma}_{0} \circ \boldsymbol{W} & \cdot & 0 \\ \cdot & \cdot & \cdot \\ 0 & . & \delta_{M} \boldsymbol{\Gamma}_{M} \circ \boldsymbol{W}\end{array}\right]+\left[\begin{array}{ccc}\delta_{0} \boldsymbol{B}_{0} \circ \boldsymbol{\Gamma}_{0} \circ \boldsymbol{W} & \cdot & \delta_{M} \boldsymbol{B}_{0} \circ \boldsymbol{\Gamma}_{M} \circ \boldsymbol{W} \\ \cdot & \cdot & \cdot \\ \delta_{0} \boldsymbol{B}_{M-1} \circ \boldsymbol{\Gamma}_{0} \circ \boldsymbol{W} & \cdot & \delta_{M} \boldsymbol{B}_{M-1} \circ \boldsymbol{\Gamma}_{M} \circ \boldsymbol{W} \\ \delta_{0} \boldsymbol{B}_{M^{\prime}} \circ \boldsymbol{\Gamma}_{0} \circ \boldsymbol{W} & . & \delta_{M} \boldsymbol{B}_{M^{\prime}} \circ \boldsymbol{\Gamma}_{M} \circ \boldsymbol{W}\end{array}\right]$,

where the symbol $\circ$ denotes the element-by-element product of two vectors or matrices (also known as the Hadamard product). Furthermore,

$\boldsymbol{\Gamma}_{m}=\left[\begin{array}{ccc}\gamma_{1 m} & \cdot & \gamma_{1 m} \\ \cdot & \cdot & \cdot \\ \gamma_{N m} & \cdot & \gamma_{N m}\end{array}\right]$ and $\boldsymbol{B}_{m}=\left[\begin{array}{ccc}\beta_{1}^{m} & \cdot & \beta_{1}^{m} \\ \cdot & \cdot & \cdot \\ \beta_{N}^{m} & \cdot & \beta_{N}^{m}\end{array}\right]$ for $m=0, \ldots, M$

where $\beta_{i}^{m}(i=1, \ldots, N ; m=0, \ldots, M-1)$ is defined by Eq. $(16)$, and $\gamma_{i m}(i=1, \ldots, N ; m=0, \ldots, M)$ is defined after Eq. (20). Finally, the elements $\beta_{i}^{m}$ of the matrix $\boldsymbol{B}_{M}(m=M)$ should be calculated as $\beta_{i}^{M}=\beta_{M 0}+\sum_{g=1}^{G} \beta_{M g} X_{i g}=1-\sum_{m=0}^{M-1} \beta_{m 0}-\sum_{g=1}^{G}\left(\sum_{m=0}^{M-1} \beta_{m g}\right) X_{i g}$ to account for the adding-up restrictions in (20c).

$\boldsymbol{\Omega}=\left[\sigma_{i j}\right]$ can be estimated by its first-order maximizing condition, $\hat{\boldsymbol{\Omega}}=\frac{1}{N} \sum_{i=1}^{N} \boldsymbol{e}_{i} \boldsymbol{e}_{i}^{T}$, where $\boldsymbol{e}_{i}$ is a $M \times 1$ vector of residuals of the $M$ equations in the system of jurisdiction $i$. Upon inserting $\hat{\boldsymbol{\Omega}}$ into the log-likelihood function, the concentrated log-likelihood function of the $\alpha, \beta$ and $\delta$ parameters is obtained

$$
\log L_{C}=C-\frac{\mathrm{N}}{2} \ln \left(\frac{1}{N} \sum_{i=1}^{N} \boldsymbol{e}_{i} \boldsymbol{e}_{i}^{T}\right)+\ln |\boldsymbol{J}|
$$

where $C$ is a constant not depending on $\alpha, \beta$ and $\delta$. Neither of these parameters can be solved analytically from the first-order maximizing conditions. Moreover, the maximum for one of these parameters cannot be found in isolation from the others. This implies that a numerical 
procedure must be used to find the maximum of the concentrated log-likelihood function for these parameters simultaneously. We used the routine "fminsearch" from Matlab's optimization toolbox. ${ }^{8,9}$ As starting values, we chose the parameter estimates of $\alpha, \beta$ and $\boldsymbol{\Omega}$ when estimating the LES without interaction effects, and the parameter estimates of $\delta$ when estimating each equation as a single equation with interaction effects (spatial lag model).

Finally, the asymptotic variance matrix of the parameters is computed for inference (standard errors, $\mathrm{t}$-values). This matrix is approached by the inverse of the numerical Hessian matrix using the maximum likelihood estimates of $\alpha, \beta, \delta$ and $\sigma$ using the full log-likelihood function in (22). ${ }^{10}$

\section{EVIDENCE OF FISCAL POLICY INTERDEPENDENCE IN THE NETHERLANDS}

\section{Local Government Finance in the Netherlands}

There are three territorial levels of government in the Netherlands: central government, provinces (12) and municipalities (496 in 2002). Each level covers the whole country; all provinces and all municipalities more or less face the same responsibilities and have the same tax options. Dutch municipalities, with 32,000 inhabitants on average, are relatively large compared to those in other countries. Municipalities, which spend eleven percent of GDP, provide many of the services that are of daily importance to citizens: from sewers to refuse collection, from local roads to poverty relief. Education, Health and Social Services (31\% of net expenditures) and Art, Leisure and Green space (23\%) are the most important expenditure categories, followed by Roads, Waterways and Monuments (19\%), Administration (10\%), Fire Brigade and Civil Protection (10\%) and Welfare (8\%).

Dutch municipalities finance their spending through specific (37\%) and general grants (30\%) from the central government, municipal levies (14\%) and income from property and market activities (19\%). ${ }^{11}$ Specific grants are received from different central government departments and are earmarked to finance local government tasks imposed by the central government, whereas general grants are used to finance the autonomous tasks of local governments. General grants are formula-based and independent of local spending and taxation. Municipal levies consist of user charges (mainly for sewerage and garbage collection) and local taxes (57\%). Local tax revenue is dominated by the property tax ( $83 \%$ of tax revenue). The only other local tax of any importance is the parking tax, which cannot be raised easily for fear of discouraging potential visitors of local businesses. Since user charges 
are not allowed to exceed (budgeted) costs and municipal budgets must be balanced, higher service levels can only be funded by raising taxes, i.e., by setting higher property tax rates.

Tax rates and expenditure levels are set by the municipal council, which is elected every four years through a system of proportional representation. The first proposals are circulated in the Spring of the preceding year. A provisional budget is presented to the council in September. In November, the council should approve the (modified) budget. During the fiscal year, the budget may be modified again, although tax rates cannot be raised any more. This procedure leaves ample room for municipalities to react to each other's (proposed) policies.

\section{Data and variables}

To estimate the LES extended to include interaction effects and spending need differences, we use cross-sectional data from 496 municipalities in 2002. Earlier studies on fiscal interaction based on single equation models either use cross-sectional data or panel data. Panel data studies offer the opportunity to control for non-observed local characteristics, which do not vary over time. If spatial fixed or random effects are added to each equation within the LES to account for these characteristics, the estimation procedure may be further extended along the lines of Elhorst (2003).

We use cross-sectional data for two reasons. First, the available data are not comparable over time as a result of the adoption of new accounting and reporting rules and the introduction of a VAT compensation fund. The second reason is the ongoing process of mergers and amalgamations, as a result of which a panel would have many observations missing. In a spatial model, this is problematic because it not only limits the number of observations, but also the number of spatial units in the spatial weights matrix used as points of reference for each observation.

We distinguish seven spending categories, which are listed in Table 1. One of these is property tax revenue, which is treated as a negative expenditure. The spending categories are defined in such a way that they may be considered net substitutes, as is required when the Stone-Geary function is applied. Since a large part of municipal spending is financed through earmarked grants and user charges that are not allowed to exceed (budgeted) costs, municipal gross expenditures may appear spatially correlated, not because municipalities are behaving strategically, but because they are reacting in a similar fashion to central government policies. Therefore, we use net expenditures, which are calculated, for each category, as total outlays 
minus earmarked grants and user charges per capita. By considering net expenditures, we are considering decisions over which municipalities have freedom of choice.

Discretionary spending on each type of public service is taken as depending on the same three exogenous variables ( $X_{g}$ in Eq. 16):

1. The share of right-wing parties in the municipal council.

2. Average disposable household income.

3. The tax price, defined as the proportion of the property tax burden associated with residential property.

Table 1 reports the variables that have been included to explain committed expenditures on each public service $\left(S_{m h}\right.$ in Eq. 17). ${ }^{12}$ Note that, for reasons of identification, each type of public service must have a unique set of determinants. These variables have been selected from a detailed set of about fifty criteria used by the central government to distribute general grants among municipalities in order to minimize both fiscal disparities and the municipalities' ability to influence their share. Since not all these characteristics appeared to be significant, we have reduced their number. The variables used to explain committed expenditures include determinants of the local demand for public services (e.g., number of schoolchildren and number of potential users in the jurisdiction's catchment area) and variables influencing the costs of producing public services (e.g., address density, which influences the costs of building and maintaining infrastructure).

$<<$ Table 1 about here $>>$

All data originate from Statistics Netherlands, ${ }^{13}$ except for tax price, which was calculated using property tax rates collected by the Center for Research on Local Government Economics (COELO) and property values supplied by Statistics Netherlands.

\section{Estimation results}

In this section we answer three basic questions. First, does the simultaneous equations model (LES) extended to include interaction effects and spending need differences describe the data well? Second, are there any differences between the interaction parameter estimates $(\delta)$ of the simultaneous equations model and those of single equation models explaining expenditures on one particular public service, independent of other types of public services, such as in previous studies reported in endnote 1? Third, are there any differences between the committed expenditures and discretionary income parameters using simultaneous equations 
models with or without interaction effects and spending need differences? These questions will be answered using the estimation results reported in Table 2 . The results of the single equation models with interaction effects will be denoted by "SE", of the LES without interaction effects and spending need differences by "LES", and of the LES with interaction effects and spending need differences by "LESextended". The single equation models with interaction effects are obtained by imposing restrictions (21a)-(21d), to get

$$
E_{i m}=\sum_{j=1}^{N} \delta_{m} w_{i j} E_{j m}+\alpha_{m 0}+\sum_{h=1}^{H_{m}} \alpha_{m h} S_{i m h}+\left(\beta_{m 0}+\sum_{g=1}^{G} \beta_{m g} X_{i g}\right) \Pi_{i}, \quad m=0, \ldots, M
$$

The LES without interaction effects and spending need differences is obtained by setting $\delta_{i}=0$ for $m=0, \ldots, M$ (note that the $\gamma$ parameters are omitted as a result).

The committed expenditures in the LES with interaction effects and spending need differences of the representative municipality will be measured as the average value over all municipalities (see Eqs. 20a-20b)

$$
\alpha_{L E S e x t e n d e d}^{m} \equiv \frac{1}{N} \sum_{i=1}^{N}\left[\gamma_{i m} \sum_{j=1}^{N} \delta_{m} w_{i j} E_{j m}+\alpha_{m 0}+\sum_{h=1}^{H_{m}} \alpha_{m h} S_{i m h}\right]
$$

Using (17), we also have $\ddot{\alpha}_{L E S \text { extended }}^{m}=\frac{1}{N} \sum_{i=1}^{N} \ddot{\alpha}_{i}^{m}=\frac{1}{N} \sum_{i=1}^{N}\left(\alpha_{m 0}+\sum_{h=1}^{H_{m}} \alpha_{m h} S_{i m h}\right)$, which denotes the committed expenditures excepting the cross-product between the interaction effects and spending need differences. In the LES without interaction effects and spending need differences $\delta_{m}=0(m=0, \ldots, M)$, as a result of which we have $\ddot{\alpha}_{L E S}^{m} \equiv \frac{1}{N} \sum_{i=1}^{N} \ddot{\alpha}_{i}^{m}$. We will report $\alpha_{L E S e x t e n d e d}^{m}, \ddot{\alpha}_{L E S e x t e n d e d}^{m}$, and $\ddot{\alpha}_{L E S}^{m}$, as well as compare $\alpha_{L E S e x t e n d e d}^{m}$ and $\ddot{\alpha}_{L E S e x t e n d e d}^{m}$ with their counterpart $\ddot{\alpha}_{L E S}^{m}$ in the LES without interaction effects and spending need differences.

Just as in most previous studies, the spatial weights matrix $\mathbf{W}$ used in the estimations is a row-normalized binary contiguity matrix. ${ }^{14}$ The expenditure category and the mean value of each expenditure category measured on a per capita basis are reported in the first two columns of Table 2.

$<<$ Table 2 about here $>>$ 
From the bottom row of Table 2 it appears that the simultaneous equations model extended to include interaction effects and spending need differences (LESextended) best describes the data. The highest value of the log-likelihood function is found when adopting this model specification (panel 3 of Table 2). ${ }^{15}$ Most of the $51 \alpha$ and $\beta$ parameters are significant ( $85 \%$ of the $\alpha$ parameters and $67 \%$ of the $\beta$ parameters) and have the expected sign. For reasons of space, we do not report these 51 separate $\alpha$ and $\beta$ parameter estimates, ${ }^{16}$ but the average value over all municipalities of their compounds according to Eqs. (16), (17) and (25). The (Dhrymes) $R^{2}$ of the system is 0.59 , while the $R^{2}$ of the separate equations that together form this system varies from 0.32 to 0.75 . All interaction parameters $(\delta)$, committed expenditures parameters ( $\ddot{\alpha}_{L E S e x t e n d e d}^{m}$ and $\alpha_{L E S e x t e n d e d}^{m}$, that is, excluding and including the crossproduct between interaction effects and spending need differences, respectively), and discretionary income spending parameters $\left(\beta^{\mathrm{m}}\right)$ appear to be significant. As noted below Eq. (13), the Stone-Geary function is only defined if $Q_{m}>\alpha^{m}$. Table 2 shows that the average expenditures on each public service $\left(p_{m} \bar{Q}_{m}\right)$ are greater than the corresponding committed expenditures parameter $\left(\alpha_{L E S e x t e n d e d}^{m}\right)$, which implies that $\bar{Q}_{m}>\alpha^{m}$. In sum, our findings illustrate that the model describes the data reasonably well.

Panels 1 and 3 of Table 2 show that the interaction effects $(\delta)$ of the single equations models and of the extended LES differ from each other. The test statistic of the hypothesis $H_{0}: \delta_{0}^{L E S e x t e n d e d}=\delta_{0}^{S E}, \ldots, \delta_{6}^{L E S e x t e n d e d}=\delta_{6}^{S E}$ has an $F$-distribution with 7 (number of restrictions) and 496-58 (number of observations minus number of response parameters) degrees of freedom and takes the value of 2.89 , which is greater than the critical value of 2.01 at five or of 2.64 at one percent significance. This points out that the differences are significant. Figure 1 compares the interaction effects of the simultaneous equations model with the corresponding estimates of the single equation models. The Figure shows that a partial analysis of fiscal policy interaction in spending levels or taxation using the spatial lag model risks underestimating the degree of interaction. On average, the interaction effects in the single equation models are underestimated by $35 \%$. Furthermore, using single equation models would wrongly reject policy interaction in 2 of the 7 service sectors under study.

Figure 1 about here

The differences between the results in panel 1 and panel 3 of Table 2 arise because the coefficient of a spatially lagged dependent variable in a single equation model suffers from 
omitted variable bias, and because accounting for differences in spending needs leads to a non-linear structure of the model. The econometric literature has pointed out that if one or more relevant explanatory variables are omitted from a regression equation, the estimator of the coefficients of the remaining variables is biased and inconsistent (Greene, 2003, pp. 148149). In the single equation model, the expenditure level of each service sector, $E_{m}$, is regressed on the discretionary income variables $X_{g}$ and the cost variables $S_{m h}$ related to $E_{m}$, while in the simultaneous equations model $E_{m}$ is also regressed on cost variables of other public services in the municipality itself and on cost variables of public services in neighboring municipalities. This extension of the number of explanatory variables is prompted by the local government's budget constraint. To the extent that these additional cost variables are significant, as most of them are according to our estimation, they are relevant variables that have been omitted from the single equation models.

Figure 1 also shows that the confidence intervals of the interaction effects in the single equation models are usually larger than those of the spatially extended LES. On average, the confidence intervals reduce by $19 \%$ when both the local government's budget constraint and differences in spending needs are accounted for. This is because the former approach implicitly assumes that the model in Eq. (20) comprises of a set of regression equations that are independent of one another, while the LES approach takes account of the nonzero correlations between the error terms of the different equations of this model (20d) that is fundamental to the SUR specification (Srivastava and Giles, 1987).

Panels 2 and 3 of Table 2 show that the parameters $\ddot{\alpha}_{L E S}^{m}$ of the LES without interaction effects and spending need differences and their counterparts $\ddot{\alpha}_{L E S \text { extended }}^{m}$ of the extended LES differ from each other. The test statistic of the hypothesis $H_{0}: \ddot{\alpha}_{\text {LESextended }}^{0}=\ddot{\alpha}_{L E S}^{0}, \ldots, \ddot{\alpha}_{L E S \text { extended }}^{6}=\ddot{\alpha}_{L E S}^{6}$ takes the value of 9.53, which means that this hypothesis must be rejected. ${ }^{17}$ The explanation is that the cross-product between the interaction effects and spending need differences ${ }^{18}$ competes with the cost determinants $S$ explaining the committed expenditures and that an omitted variable bias occurs if this crossproduct is not accounted for. On average, the parameters $\ddot{\alpha}_{L E S}^{m}$ in the LES without interactions and spending need differences are overestimated by $21 \%$ (in absolute value). One may also test whether $\ddot{\alpha}_{L E S}^{m}$ are different from the committed expenditures in the extended LES, $\alpha_{L E S e x t e n d e d}^{m}$, as defined in (26). The test statistic of the corresponding hypothesis 
$H_{0}: \alpha_{\text {LESextended }}^{0}=\ddot{\alpha}_{L E S}^{0}, \ldots, \alpha_{L E S \text { extended }}^{6}=\ddot{\alpha}_{L E S}^{6}$ takes the value of 1.90 , which points out that this hypothesis cannot be rejected.

Finally, we consider the question whether including interaction effects and spending need differences in the LES affects the estimates of discretionary spending. For the discretionary income spending parameters the following pattern emerges from Table 2: $\beta_{\mathrm{LES} \text { extended }}^{\mathrm{m}} \approx \beta_{L E S}^{m}$. In other words, ignoring interaction effects in the LES has little effect on the discretionary income spending parameters. The test statistic of the hypothesis that the discretionary income spending parameters in the the LES without interaction effects and spending need differences are equal to those in the extended LES takes the value of 2.01 (panel 2 vs. panel 3). This value is just equal to the critical value at the $5 \%$ significance level so that the hypothesis cannot be rejected. This finding can be explained by the fact that the interaction effects were not made part of the discretionary income spending parameters $\beta^{\mathrm{m}}$ and therefore do not compete with the discretionary income variables $Z$.

\section{$5 \quad$ CONCLUSION}

Interaction among spending levels in one particular public service sector should not be studied in isolation from other public services or from tax revenue, and tax interdependence should not be studied without taking possible spending interactions into account. Previous studies have done just that, usually relying on single equation models including a spatial lag. Such models ignore relevant cost variables of other public services prompted by the local government's budget constraint, as well as differences in spending needs between jurisdictions. Using Dutch municipal data, we find that such models downwardly bias the degree of spatial interaction. Using single equation models would wrongly reject policy interaction in 2 of the 7 service sectors we studied. Moreover, in single equation models, the degree of interaction is estimated inefficiently. In the extended LES we developed, the equations are linked by the error terms, as a result of which efficiency is gained by estimating the equations simultaneously. All this implies that the results of previous studies may have to be reconsidered.

In future research it would be of interest to extend the analysis of this paper to panel data along the lines of Elhorst (2003), and to test which (combination of) theories, expenditure spillovers, yardstick competition or tax/expenditure competition, can explain interdependent fiscal behavior of local governments. To test whether yardstick competition is 
the mechanism behind tax or expenditure mimicking, each equation may be further extended to two spatial regimes as in Bordignon et al. (2003) or Allers and Elhorst (2005). 


\section{REFERENCES}

Aaberge, R., Langørgen, A., 2003. "Fiscal and Spending Behavior of Local Governments: Identification of Price Effects When Prices Are Not Observed", Public Choice, 117, 125-61.

Allers, M.A., Elhorst, J.P., 2005. "Tax Mimicking and Yardstick Competition Among Local Governments in the Netherlands", International Tax and Public Finance, 12, 493-513.

Anselin, L., 1988. Spatial Econometrics: Methods and Models. Dordrecht: Kluwer.

Anselin, L., 2006. "Spatial Econometrics", in Mills, T., Patterson, K. (eds), Palgrave Handbook of Econometrics, vol. 1. Basingstoke: Palgrave McMillan, pp. 901-969.

Anselin L., Bera, A. (1998) "Spatial Dependence in Linear Regression Models with an Introduction to Spatial Econometrics", in Ullah, A., Giles. D. (eds), Handbook of Applied Economics Statistics,. New York, Marcel Dekker pp. 237-289.

Anselin, L., Bera, A.K., Florax, R., Yoon, M.J., 1996. "Simple Diagnostic Tests for Spatial Dependence", Regional Science and Urban Economics, 26, 77-104.

Baicker, K., 2005. "The Spillover Effects of State Spending", Journal of Public Economics, $89,529-544$.

Barnum, H.W., Squire, L., 1979. "An Econometric Application of the Theory of the FarmHousehold", Journal of Development Economics, 6, 79-102.

Bennett, R.J., 1984. "A Bureaucratic Model of Local Government Tax and Expenditure Decisions", Applied Economics, 16, 257-268.

Besley, T., Case, A., 1995. "Incumbent Behavior: Vote-Seeking, Tax-Setting, and Yardstick Competition", American Economic Review, 85, 25-45.

Boarnet, M, Glazer, A., 2002. "Federal Grants and Yardstick Competition", Journal of Urban Economics, 52, 53-64.

Bordignon, M., Cerniglia, F., Revelli, F., 2003. "In Search of Yardstick Competition: A Spatial Analysis of Italian Municipal Property Tax Setting", Journal of Urban Economics, 54, 199-217.

Brock, W.A, Durlauf, S.N., 2001. "Interactions-Based Models", in Heckman, J.J., Leamer, E. (eds), Handbook of Econometrics, Vol. 5. Amsterdam: Elsevier, pp. 3297-3380.

Brueckner, J.K., 2003. "Strategic Interaction among Governments: An Overview of Empirical Studies", International Regional Science Review, 26, 175-188.

Case, A.C., Rosen, H.S., Hines, J.R., 1993. "Budget Spillovers and Fiscal Policy Interdependence", Journal of Public Economics, 52, 285-307.

Cuthbertson, K., Foreman-Peck, J.S., Gripaios, P., 1981. “A Model of Local Authority Fiscal Behaviour", Public Finance, 21, 229-243.

Eastwood, D.B., 1987. "An Adaptive Linear Expenditure System for State and Local Governments", Applied economics, 10, 279-287.

Elhorst, J.P., 2003. "Specification and Estimation of Spatial Panel Data Models", International Regional Science Review, 26, 244-268.

Figlio, D.N., Kolpin, V.W., Reid, W.E., 1999. "Do States Play Welfare Games?", Journal of Urban Economics, 46, 437-454.

Finney, M.M., Yoon, M.J., 2003. "Asymmetric Interdependence in the Provision of a Local Public Good: An Empirical Examination”, Public Finance Review, 31, 648-668.

Florax, R.J.G.M., Folmer, H., 1992. "Specification and Estimation of Spatial Linear Regression Models", Regional Science and Urban Economics, 22, 405-432.

Foucault, M., Madies, T., Paty, S., 2008. "Public spending interactions and local politics. Empirical evidence from French municipalities", Public Choice, 137, 57-80. 
Gaertner, W., 1974. "A Dynamic Model of Interdependent Consumer Behavior”, Zeitschrift für Nationalökonomie, 34, 327-344.

Geys, B., 2006. "Looking across borders: A test of spatial policy interdependence using local government efficiency ratings", Journal of urban economics, 60, 443-462.

Greene, W.H., 2003. Econometric Analysis, fifth edition. New Jersey: Prentice Hall.

Grodner, A., Kniesner, T.J., 2006. "Social Interactions in Labor Supply", Journal of the European Economic Association, 4, 1226-1248.

Hanes, N., 2002. "Spatial Spillover Effects in the Swedish Local Rescue Services", Regional Studies, 36, 531-539.

Inman, RP., 1971. "Towards an Econometric Model of Local Budgeting", Proceedings of the Annual Conference on Taxation, National Tax Association, 699-719.

Jackman, R, Papadachi, J., 1981. "Local Authority Education Expenditure in England and Wales: Why Standards Differ and the Impact of Government Grants", Public Choice, 36, 425-439.

Johnson, M.B., 1979. "Community Income, Intergovernmental Grants, and Local School District Fiscal Behavior", in Mieszkowski, P., Oakland, W.H. (eds), Fiscal Federalism and Grants-in-Aid. Washington, D.C : The Urban Institute, pp. 51-77.

Kapteyn, A., Van de Geer, S., Van de Stadt, H., Wansbeek, T., 1997. "Interdependent Preferences: An Econometric Analysis", Journal of Applied Econometrics, 12, 665-686.

Kelejian, H.H., Prucha, I.R., 2004. "Estimation of Simultaneous Systems of Spatially Interrelated Cross-sectional Equations", Journal of Econometrics, 118, 27-50.

Kelejian, H.H., Robinson, D.P., 1993. "A Suggested Method of Estimation for Spatial Interdependent Models with Autocorrelated Errors, and an Application to a County Expenditure Model", Papers in Regional Science, 72, 297-312.

Kooreman, P., Schoonbeek, L., 2004. "Characterizing Pareto Improvements in an Interdependent Demand System", Journal of Public Economic Theory, 6, 427-443.

Ladd, H.F., Yinger, J., 1994. "The case for equalizing aid”, National Tax Journal, 47, 211224.

Lee, L.-F., 2004. "Asymptotic distribution of quasi-maximum likelihood estimators for spatial autoregressive models", Econometrica, 72, 1899-1925.

LeSage, J.P., Pace R.K. 2009. Introduction to Spatial Econometrics. CRC Press/Taylor \& Francis Group.

Lundberg, J., 2006. "Spatial Interaction Model of Spillovers from Locally Provided Public Services", Regional Studies, 40, 631-644.

Magnus, J.R., Neudecker, H., 1988. Matrix Differential Calculus with Applications in Statistics and Econometrics. Chichester: John Wiley.

Manski, C., 1993. "Identification of Endogenous Social Effects: The Reflection Problem", Review of Economic Studies, 60, 531-542.

Ministry of Home Affairs and Ministry of Finance, 2002. Vaststelling van de begrotingsstaat van het gemeentefonds voor het jaar 2003. The Hague, Tweede Kamer, 2002-2003, 28600 B, nr. 2.

Ministry of Finance, 2002. Miljoenennota 2003. The Hague, Tweede Kamer, 2002-2003, 28600, nr. 2.

Moffitt, R.A., 2001. "Policy Interventions, Low-Level Equilibria, and Social Interactions", in Durlauf S.N., Young H.P. (eds), Social Dynamics.Cambridge, M.A. and London: Brookings Institution Press.

Murdoch, J.C., Rahmatian, M., Thayer, M.A., 1993. "A Spatially Autoregressive Median Voter Model of Recreation Expenditures", Public Finance Quarterly, 21, 334-350.

Pollak, R.A., 1976. “Interdependent Preferences", American Economic Review, 66, 309-320. 
Pollak, R.A., Wales, T.J., 1981. "Demographic Variables in Demand Analysis", Econometrica, 49, 1533-1551.

Revelli, F., 2002. "Testing the Tax Mimicking versus Expenditure Spill-Over Hypothesis Using English Data", Applied Economics, 34, 1723-1731.

Revelli, F., 2005. "On Spatial Public Finance Empirics", International Tax and Public Finance, 12, 475-492.

Revelli, F., 2006. "Performance Rating and Yardstick Competition in Social Service Provision", Journal of Public Economics, 90, 459-475.

Revelli, F., Tovmo, P., 2007. "Revealed yardstick competition: Local government efficiency patterns in Norway", Journal of Urban Economics, 62, 121-134.

Saavedra, L.A., 2000. "A Model of Welfare Competition with Evidence from AFDC", Journal of Urban Economics, 47, 248-279.

Salmon, P., 1987. "Decentralisation as an Incentive Scheme", Oxford Review of Economic Policy, 3, 24-43.

Schaltegger, C.A., Küttel, D., 2002. "Exit, Voice, and Mimicking Behavior: Evidence from Swiss Cantons", Public Choice, 113, 1-23.

Soetevent, A.R., 2004. Social Interactions and Economic Outcomes. Ridderkerk: Labyrint Publications.

Soetevent, A.R., 2006. "Empirics of the Identification of Social Interactions; An Evaluation of the Approaches and Their Results", Journal of Economic Surveys, 20, 193-228.

Solé-Ollé, A., 2006. "Expenditure Spillovers and Fiscal Interactions: Empirical Evidence from Local Governments in Spain", Journal of Urban Economics, 59, 32-53.

Srivastava, V.K., Giles, D.E.A., 1987. Seemingly Unrelated Regression Equation Models. New York : Marcel Dekker.

Stakhovych, S., Bijmolt, T.H.A., 2009. "Specification of Spatial Models: A Simulation Study on Weights Matrices", Papers in Regional Science, 88, 389-408.

Stone, J.R.N., 1954. "Linear Expenditure Systems and Demand Analysis: An Application to the Pattern of British Demand", Economic Journal, 64, 511-527.

Tao, J., 2005. Spatial Econometrics: Models, Methods and Applications, Ph.D. dissertation, Ohio State University.

Tiebout, C.M., 1956. "A Pure Theory of Local Expenditures", Journal of Political Economy, 64, 416-424.

Werck, K., Heyndels, B., Geys, B., 2008. "The impact of 'central places' on spatial spending patterns: evidence from Flemish local government cultural expenditures", Journal of Cultural Economics, 32, 35-58.

Wilson, J.D., 1999. “Theories of Tax Competition”, National Tax Journal, 52, 269-304. 
Property tax base: the value of taxable property (per capita)

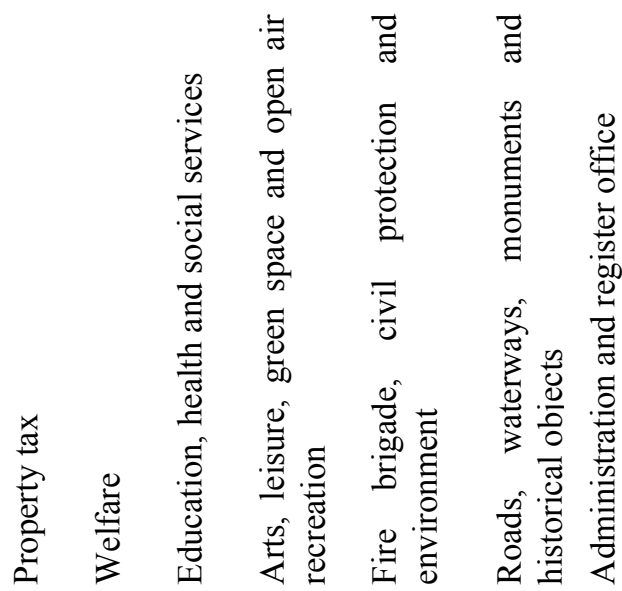

Share of low-income households

Number of welfare recipients (per capita)

Average number of welfare recipients in 1996-1998 (per capita)

Number of schoolchildren (per capita).

Number of potential users in the local catchment area $^{1}$

Number of potential users in the regional catchment area (per capita) ${ }^{2}$

Proportion of social security benefit recipients $^{3}$

Proportion of inhabitants from ethnic minorities

Number of residences (per capita)

Bank or shore length adjusted for soil condition (per capita)

Built-up area (per capita)

Address density ${ }^{4}$

Number of business establishments (per capita)

Area of historical town center (per capita)

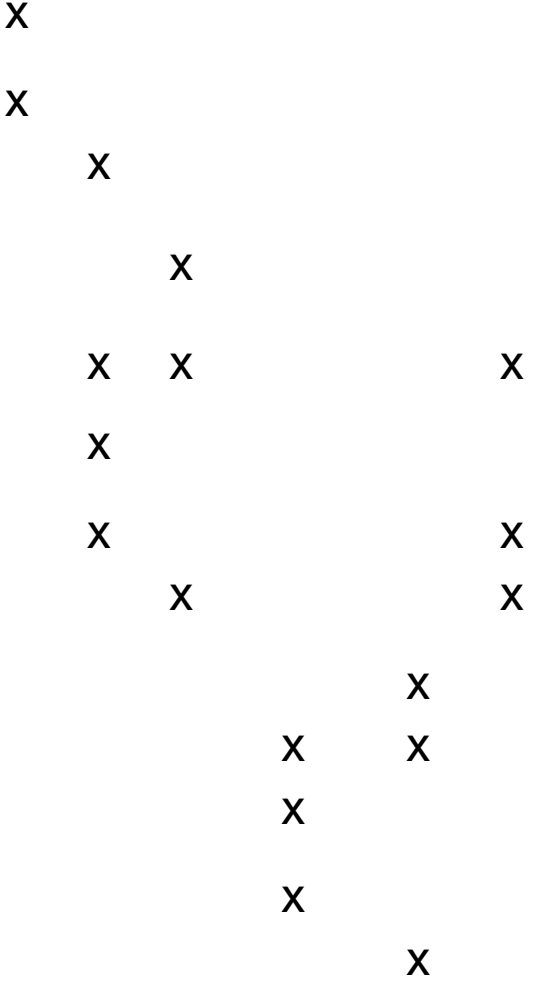

1 Number of potential users of municipal services within a radius of twenty kilometers. This variable increases linearly with the number of inhabitants and decreases with the square of the distance. The total number of potential users for all municipalities equals the number of inhabitants of the country.

2 Number of potential users of municipal services within a radius of sixty kilometers.

3 Including welfare, unemployment benefit and disability benefit.

4 Average number of addresses per square kilometer within a radius of one kilometer. 
Table 2: Main estimation results

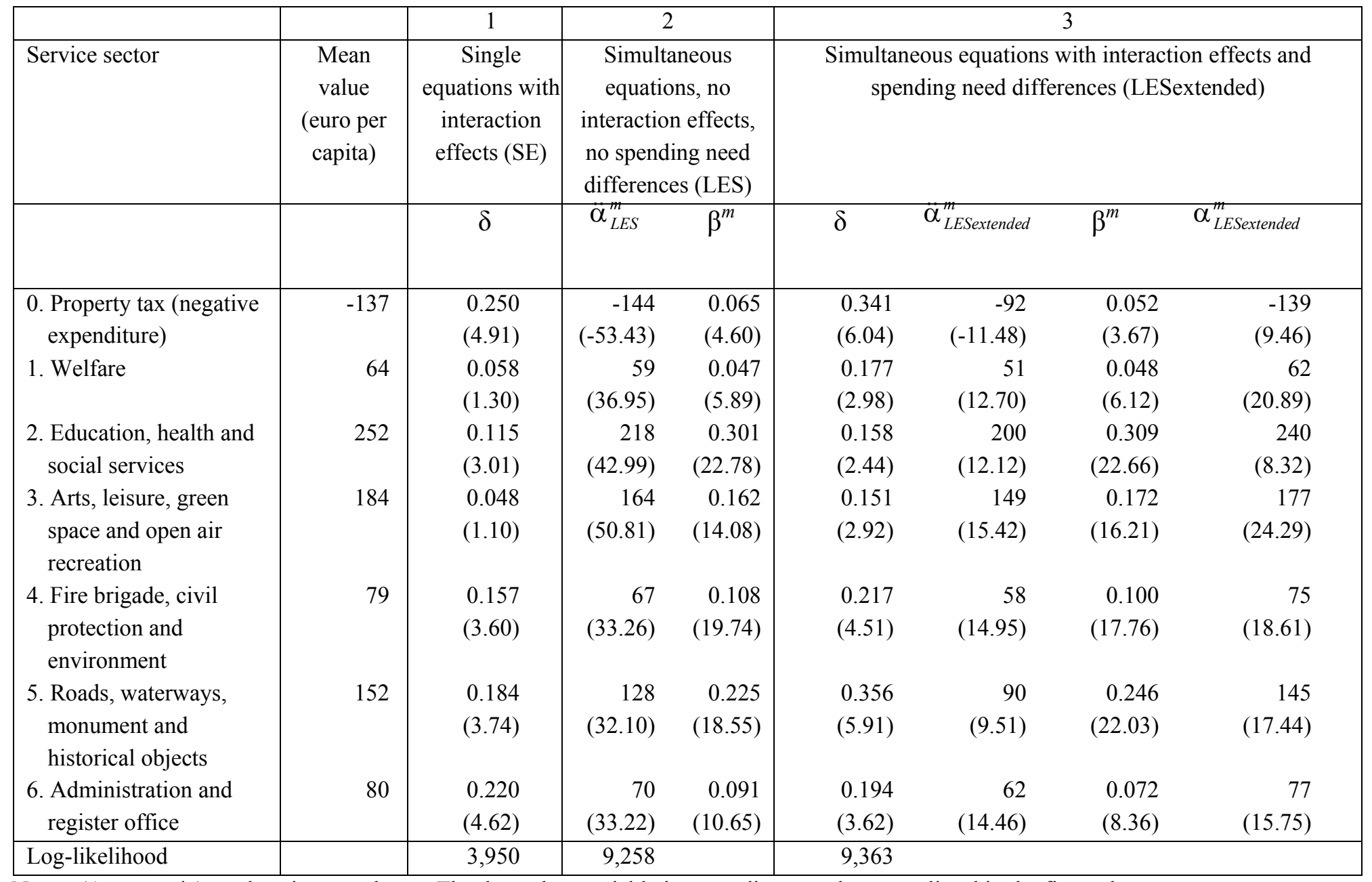

Notes: (Asymptotic) t-values in parentheses. The dependent variable is expenditure on the sector listed in the first column.

$\alpha_{L E S e x t e n d e d}^{m}$ is defined by (26) and $\ddot{\alpha}_{L E S e x t e n d e d}^{m}$ and $\ddot{\alpha}_{L E S}^{m}$ are defined below (26). 
Figure 1: Parameter estimates of interaction effects $(\delta)$ and $95 \%$ confidence intervals from Table 2. Dotted lines represent the estimates of single equation models (SE). Solid lines represent LES estimates where both the local government's budget constraint and differences in spending needs are accounted for (LESextended).

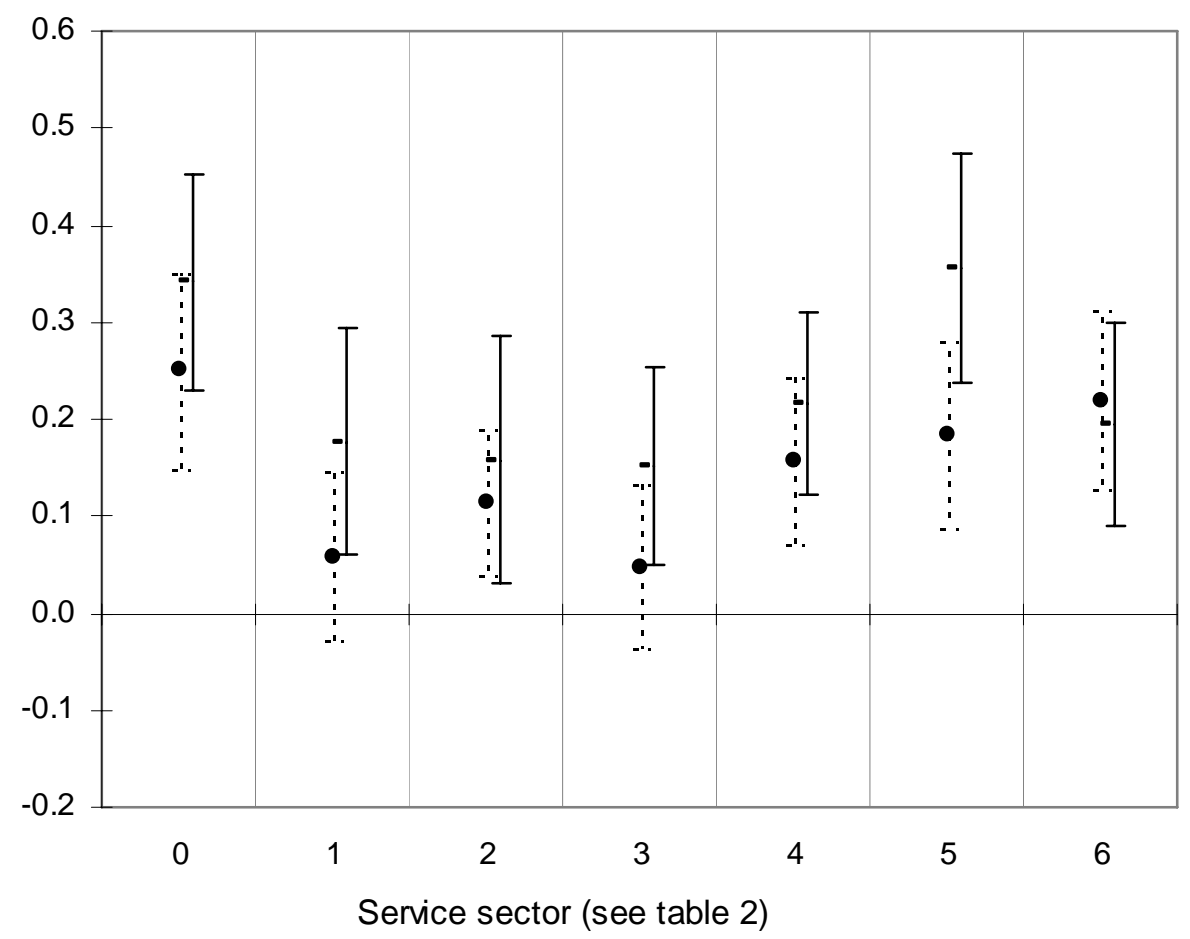


${ }^{1}$ Allers and Elhorst (2005) give an overview and references of tax interaction studies. Regarding expenditure interaction, Kelejian and Robinson (1993) studied police spending in the U.S. (interaction effect 0.3), Murdoch et al. (1993) recreation spending in municipalities in the Los Angeles area (0.4), Case et al. (1993) total spending in US states (0.7), Figlio et al. (1999) welfare benefit levels in US states (not significant), Saavedra (2000) welfare benefit levels in US states (positive, magnitude depends on year and spatial weights), Revelli (2002) total spending in English metropolitan districts (0.2), Hanes (2002) rescue services in Swedish municipalities (negative, magnitude depends on specification), Schaltegger and Küttel (2002) total spending in Swiss cantons (0.7), Finney and Yoon (2003) library spending in municipalities and counties in Los Angeles area (negative, magnitude depends on specification), Baicker (2005) total expenditure on social services (1.0), Tao (2005) school district spending in Ohio (insignificant), Solé-Ollé (2005) overall spending in Spanish municipalities (magnitude depends on specification and authority type), Lundberg (2006) spending on recreational and cultural services (negative, magnitude depends on specification), Revelli (2006) personal social services of local authorities in England ( 0.2 before introduction of national performance assessment system, not significant afterwards), Werck et al. (2008) cultural spending of Flemish municipalities (positive, and stronger between municipalities that are not central places), and Foucault et al. (2008) spending of French municipalities (positive, depending on spending category). Finally, Boarnet and Glazer (2002) find that spending of U.S. states depends negatively on grants received by neighboring states as a result of yardstick competition.

${ }^{2}$ Throughout this paper, we use both "spending needs" and "unit costs" to mean the expenditures needed to provide a certain service level. These may differ between localities as a result of production cost differences (operating a school is more expensive in a cold climate than in a moderate one) and as a result of demographic differences (jurisdictions with a larger proportion of school age children need to spend more per capita to attain a certain educational service level than other jurisdictions).

${ }^{3}$ An LES was first estimated by Stone (1954). Applications of this model to local government decision-making (but without policy interaction) are found in Aaberge and Langørgen (2003), Bennet (1984), Cuthbertson et al. (1981), Eastwood (1978), Inman (1971), Jackman and Papadachi (1981), and Johnson (1979). 
${ }^{4}$ Examples of more flexible systems are the almost ideal demand system (AIDS) and the translog system. A system is called flexible if it has enough parameters to be regarded as a reasonable approximation to whatever the true unknown system may be. More flexible systems, however, require either prices for each expenditure category at each jurisdiction when having cross-sectional data or prices for each expenditure category at the national level when having space-time data over a sufficient long time span. Most studies on fiscal policy interaction do not meet this requirement.

${ }^{5}$ In the social interaction literature, sometimes a simple ad hoc method is used to correct for differences in unit costs. Kapteyn et al. (1997) assume that only the expenditure levels of other governments in excess of their subsistence levels raise committed expenditures. Spatial econometrics studies sometimes include control variables to account for differences in production costs of public services. Hanes (2002), e.g., includes land area of each municipality to control for transportation or thinning costs. In contrast, in our approach, spending needs are modeled explicitly. This leads to a different, non-linear, specification rather than a linear specification augmented with additional control variables.

${ }^{6} \mathrm{~A}$ few studies have been based on the spatial error model, which is a single equation model extended to include spatial interaction in the error term (Anselin, 2006).

${ }^{7}$ The linear expenditure system in its basic form is linear in the variables but nonlinear in the parameters. However, Barnum and Squire (1979) have shown that it can be rewritten in such a way that linear estimation techniques can still be used to estimate the parameters. Since the linear expenditure system extended to include interaction effects and differences in spending needs is also nonlinear in its variables, linear estimation techniques can no longer be used. The same applies to the techniques spelled out in Anselin (1988), which are partially linear.

${ }^{8}$ One problem is that computation time as a result of this Jacobian increases exponentially with the number of equations within the system. Every time the log-likelihood needs to be calculated requires less than 1 second when $\mathrm{M}=3,2.5$ seconds when $\mathrm{M}=5,7.5$ seconds when $\mathrm{M}=7$ and 15 seconds when $\mathrm{M}=9$. For this reason, we have also tried to estimate the model by methods using instrumental variables (Anselin, 1988, pp. 81-88; 
Kelejian and Prucha, 2004), just because they ignore the Jacobian term. However, we found that the spatial interaction parameters $\delta$ did have the tendency to take unrealistically high values, sometimes greater than unity. Although consistent, the major disadvantage of IV-estimators is that they are less accurate than their ML counterparts as a result of ignoring the Jacobian term.

${ }^{9}$ The Matlab code used for the estimations is available from the authors upon request.

${ }^{10}$ See LeSage and Pace (2009, Section 3.2) for a general description of this procedure. The computation of the numerical Hessian may be carried out using the Matlab routine "hessian" from LeSage's website $<$ www.spatialeconometrics.com>.

${ }^{11}$ The figures refer to 2002. Source: Ministry of Finance (2002) and Ministry of Home Affairs and Ministry of Finance (2002).

${ }^{12}$ Expenditures on sewers and refuse collection are excluded from the analysis. Since most municipalities finance these outlays from user charges, net expenditures are zero. Furthermore, spending on Housing, Planning and Urban Redevelopment is excluded, since it consists mainly of large investments followed by years of low spending. Ideally, investment spending should not turn up in the budget, only interest and depreciation. In practice, however, such investments are often written off immediately, as a result of which spending data for one particular year cannot be analyzed fruitfully.

${ }^{13}$ Data are available from http://statline.cbs.nl/statweb/?LA=en.

${ }^{14}$ Stakhovych and Bijmolt (2009) show that spatial models that use a first-order contiguity weight matrix perform better on average than do those that use other weight matrix specifications, due to their higher probabilities of detecting the true model and the lower mean standard error of the spatial and regression parameters.

${ }^{15}$ The log-likelihood of the other models is calculated using the log-likelihood function in Eq. (22) with as arguments the parameter estimates produced by these models (and zeros in case parameters do not enter into these models). 
${ }^{16}$ Available from the authors upon request.

${ }^{17}$ The degrees of freedom and critical values are the same as for the test whether the interaction effects in both models are identical.

${ }^{18}$ This is the term $\gamma_{i m} \sum_{j=1}^{N} \delta_{m} w_{i j} E_{j m}$, where $\gamma_{i m}=p_{i m} / \sum_{j=1}^{N} w_{i j} p_{j m}$. 